\title{
Percursos de estudantes da Educação Superior com trajetórias de insucesso*
}

Lourdes Maria Bragagnolo Frison (In Memorian) ${ }^{\text {a }}$ Ana Margarida Veiga Simão ${ }^{b}$ Paula da Costa Ferreira ${ }^{c}$ Paula Paulino ${ }^{d}$

\section{Resumo}

Esse estudo analisa as trajetórias de insucesso e identifica motivos, estratégias e expectativas percebidas por 38 estudantes - 19 portugueses e 19 brasileiros que elaboraram uma narrativa de autoformação e comentaram duas escalas para avaliar estratégias de autorregulação, de acordo com sua eficácia e sua utilização. Os estudantes mostram padrões de resposta semelhantes e refletem crenças e estratégias pouco adaptativas face à aprendizagem. Desmotivação, ansiedade, falta de persistência e características dos contextos universitário e familiar são percebidas como os principais motivos de insucesso. Os estudantes referem que a estratégia mais utilizada é a regulação pelas metas de resultado-evitamento e a mais eficaz, a gestão da atenção; revelam visão positiva do valor do curso para seu futuro, mas identificam uma grande discrepância entre os conteúdos lecionados e as exigências do mundo do trabalho.

Palavras-chave: Estudantes Universitários. Narrativas. Insucesso. Estratégias.

\section{Introdução}

Pesquisadores como Almeida, (2019), Beaumont, Moscrop e Canning (2014), Koivuniemi et al. (2017) e Sáez et al. (2018) destacam que ingressar na universidade é bastante crítico por estar vinculado a um processo de transição e incorporação

\footnotetext{
* Financiada pelo Conselho Nacional de Desenvolvimento Científico e Tecnológico - Projeto Universal.

a Universidade Federal de Pelotas, Pelotas, RS, Brasil.

b Faculdade de Psicologia. Universidade de Lisboa, Lisboa, Portugal.

c Faculdade de Psicologia. Universidade de Lisboa, Lisboa, Portugal.

d Faculdade de Psicologia. Universidade de Lisboa, Lisboa, Portugal.
} 
em um novo mundo social e educacional. Tudo isto gera grande instabilidade advinda de mudanças fulcrais em relação à condução e à orientação educacional da Educação Básica, altamente estruturada e controladora, provocadas pela cultura de aprendizagem autorregulada proposta na Educação Superior. A falta de mobilização de estratégias de autorregulação na aprendizagem é ponto destacado por Miranda e Guzmán (2017) e Stoten (2015), os quais expõem que os universitários iniciantes, em consequência das demandas e das exigências acadêmicas, acabam abandonando a universidade precocemente. Autores como Almeida (2019), Miranda, Nonticuri e Frison (2017), Panadero, e Alonso Tapia (2014) e Sáez et al. (2018) destacam que a universidade precisa redimensionar sua atuação para que os estudantes possam efetivamente controlar seus processos de estudo, garantindo o desenvolvimento de competências úteis para sua vida, quer acadêmica, quer externa a ela.

Ressalta-se que a grande abertura ao acesso universitário no Brasil, registrando-se, em um intervalo de 10 anos (2006/2016), o crescimento das matrículas de 4,9\% (SANTOS; FERRAZ; INÁCIO, 2019). Contudo, há poucas ações que visem a garantir a permanência dos ingressantes e seu sucesso acadêmico (ISHII, KRASILCHIK, LEITE, 2014). Muitos estudantes obtêm auxílio por meio do Programa Nacional de Auxílio ao Estudante (Pnaes), entretanto, quando surgem reprovações, eles podem perder o direito de recebê-lo. Para conservar o benefício, o estudante precisa alcançar o percentual de $70 \%$ de aprovação nas disciplinas em que esteve matriculado durante o semestre (BRASIL, 2010; INEP, 2017; MIRANDA, NOTICURI, FRISON, 2017). Em Portugal, a realidade é similar. Simão, Santos e Costa (2003) salientam que, nos últimos 30 anos, houve, na universidade, um processo de massificação discente, demarcado pela passagem do total de 40 mil universitários para 400 mil. Consequentemente, a relação com o insucesso também aumentou, havendo até 33\% de reprovações em diferentes cursos da Graduação (ALMEIDA, 2013). Entende-se insucesso acadêmico como um fenômeno abrangente, caracterizado pelo fraco rendimento dos estudantes que, por razões várias, não atingem os objetivos mínimos exigidos para concluir com êxito as etapas de sua escolaridade. O insucesso parece emergir de fatores de natureza muito diversa, com efeitos intercruzados e associados a professores, alunos, currículos, instituições, contextos pedagógico, social, cultural e econômico.

Na Educação Superior, o estudante desempenha papel ativo na procura e na seleção da informação, na compreensão e na reflexão das matérias de estudo, no planejamento das atividades, na definição dos objetivos a atingir. Todas estas ações pressupõem competências de autorregulação da aprendizagem, que contribuem para o sucesso acadêmico. 
A autorregulação da aprendizagem consiste em um processo autodirigido, no qual o estudante transforma suas habilidades mentais em habilidades acadêmicas, gerando pensamentos, sentimentos e comportamentos voltados para metas e objetivos pessoais. Ela coloca o discente no centro do processo da aprendizagem, para que o assuma e, com iniciativa, controle, perseverança e domínio de estratégias, alcance bons resultados acadêmicos (ZIMMERMAN, 2013).

A autorregulação contribuiu para que o estudante tenha melhor desempenho acadêmico, pois envolve as dimensões cognitiva/metacognitiva, comportamental motivacional e contextual. A dimensão cognitiva/metacognitiva está diretamente relacionada à competências pessoais, ao autoconceito e à autoimagem. A dimensão comportamental abarca o controle de atividades e de tarefas. A motivacional imbrica-se com a autoeficácia, os valores e os afetos do estudante relacionados à tarefa e a contextual pode afetar ou potencializar a atuação do estudante em relação a construção de metas e definição de objetivos.

Para autorregular a aprendizagem, é importante que o universitário tenha percepção temporal de sua trajetória, a qual se desenrola em um período de tempo mais ou menos alargado, de forma subjetiva, muitas vezes não consciente (BOYD; ZIMBARDO, 2005). A perspectiva temporal, além de ser um estilo cognitivo específico de abordagem das tarefas com impacto na motivação e na avaliação, tem implicações diretas no processo de tomada de decisão.

A motivação é uma dimensão importante da autorregulação, sendo seu impacto na aprendizagem amplamente reconhecido na literatura. A regulação da motivação do estudante mostra-se fundamental para a aprendizagem, pois determina o estabelecimento de objetivos e a manutenção do esforço e da persistência, estando, geralmente, associada a bons desempenhos acadêmicos (MERETT et al., 2020; WOLTERS, 2011; ZIMMERMAN; SCHUNK, 2008). Usar uma estratégia de regulação motivacional requer que o aluno tenha conhecimento sobre os fatores que influenciam a orientação para aprender, a determinação para alcançar uma meta desejada, a capacidade de refletir sobre o interesse que a tarefa tem para ele, a capacidade para monitorizá-la e avaliar a utilidade e a eficácia de sua aplicação à tarefa. O que motiva os alunos a aprender? Como se automotivam? O que fazer para ajudá-los a regular a sua motivação no contexto universitário?

De acordo com Weiner (2010), os indivíduos tendem a atribuir seus sucessos ou fracassos a fatores como competência, esforço, sorte, dificuldades inerentes à tarefa. As explicações causais podem ser agrupadas em: lócus de causalidade (interno ou externo ao indivíduo); estabilidade (estável ou potencialmente alterável ao longo 
do tempo); controlabilidade (a causa pode ser controlável). Estas atribuições pessoais parecem ser determinantes na definição de objetivos, na orientação de comportamentos e nas reações emocionais a situações futuras (WEINER, 2016).

As crenças do estudante sobre ele mesmo e sobre a tarefa e/ou sobre o ambiente interagem entre si e influenciam o comportamento que ele virá a adotar (BANDURA, 2017). Ou seja, diversos elementos do ambiente de aprendizagem influenciam a motivação dos estudantes, entre eles, os métodos de Ensino, a avaliação e o feedback dado pelo professor.

Os docentes podem agir para melhorar a motivação do estudante, mas eles referem que nem sempre alcançam êxito, pois, por vezes, os conteúdos das tarefas são considerados pelos alunos irrelevantes, difíceis ou tediosas. Qualquer uma dessas percepções desmotiva e não gera desejo ou envolvimento. Consequentemente, alguns estudantes chegam a abandonar a universidade ao se depararem com situações que lhes parecem insuperáveis (WOLTERS, 2011). Os docentes, a fim de promoverem competências que permitam aos estudantes terem papel ativo e construtivo nos processos de aprendizagem, precisam oferecer oportunidades para que os discentes interajam com o contexto acadêmico.

A literatura salienta o papel dos professores no estímulo à reflexão e à análise crítica, pela seleção de atividades pelas quais possam afetar as crenças motivacionais e o sucesso acadêmico dos estudantes. É preciso lhes oferecer modelos para que aprendam a utilizar estratégias autorregulatórias em situações cotidianas de aprendizagem, assim estimulando a atuação autônoma (ALMEIDA, 2019). Cabe aos pesquisadores o desafio de investigar intervenções que permitam formular novas práticas, com o objetivo de levar os estudantes a superarem os obstáculos.

A pesquisa foi delineada considerando várias situações às quais o estudante tem dificuldade de atender - exigências advindas da universidade, da família, do contexto social - e os condicionantes que contribuem para que ele tenha resultados pouco favoráveis em sua organização temporal. Entre suas várias causas estão a procrastinação sistemática de atividades acadêmicas; a reduzida capacidade de trabalhar em colaboração; a falta de motivação e de métodos de estudo; a quase inexistência de práticas de acolhimento pelas universidades, principalmente em relação a aspectos cognitivos, afetivos e emocionais.

Definiu-se, por conseguinte, como objetivo desta pesquisa, conhecer as trajetórias acadêmicas de estudantes com insucesso na Educação Superior, identificando motivos, estratégias e expectativas de futuro. 
Com esse intuito, foram elaboradas questões de investigação que levassem a melhor compreenção das vivências acadêmicas na Educação Superior:

- Quais motivos encontram-se implícitos nas trajetórias acadêmicas que revelam insucesso dos estudantes?

- Quais estratégias autorregulatórias são utilizadas por estudantes com trajetórias de insucesso e como avaliam a eficácia da sua aplicação?

- Quais as expectativas dos estudantes com trajetórias de insucesso em relação a seu futuro no curso?

\section{Método}

\subsection{Participantes}

Utilizou-se a técnica de amostragem não probabilística de conveniência. Realizouse um encontro acadêmico em uma universidade pública de Portugal (Distrito de Lisboa) e em uma universidade pública do Brasil (Rio Grande do Sul) para apresentar a pesquisa, onde os estudantes foram convidados a participar e a divulgar a pesquisa junto de colegas da mesma universidade. Estudantes que manifestaram disponibilidade para participar foram contemplados, desde que cumprissem o critério de inclusão na amostra, sendo que esta foi idêntica nos dois países: consistiu em ter, pelo menos, uma retenção na Educação Superior na data da recolha de dados, quer no ano da coleta, quer nos anos anteriores. Todos os estudantes que participaram deste estudo ingressaram na Educação Superior realizando provas de ingresso.

A amostra foi constituída por 19 estudantes que se interessam, sendo 11 homens e 8 mulheres de Portugal, com idades entre 20 e 34 anos, e 19 estudantes do Brasil (12 homens e 7 mulheres), com idades entre 18 e 45 anos, de diferentes áreas científicas (Ciências Sociais e Humanidades, Ciências da Saúde e da Vida, Ciências Exatas e da Engenharia).

\subsection{Instrumentos}

Narrativas de autoformação - mostram-se relevantes para entender como os estudantes alteram pensamentos, ações, sentimentos com o intuito de alcançar objetivos acadêmicos. Entende-se que narrar a própria história proporciona ao estudante a oportunidade de pensar sobre seus processos, os quais atribuem 
sentido e significado a suas escolhas e a motivações futuras. As narrativas possibilitam entender o que as causou, como encontrar o sentido sobre as escolhas e as motivações (RICOEUR, 1995) e, comportam a tríplice dimensão, integração de elementos do passado que o indivíduo considera relevantes para descrever e entender a situação presente e a perspectiva de projeção futura, e são utilizadas como recursos metodológicos, por permitirem identificar, por meio dos relatos, como os sujeitos chegaram à determinada situação, o que fazem para administrá-la e superá-la. Os estudantes foram convidados a falar sobre como se veem como estudantes (características pessoais e de Ensino que interferem em sua aprendizagem) e sobre estratégias que utilizam para estudar; como explicam seu insucesso e que expectativas têm em relação a seu futuro no curso.

\section{Escala de Autorregulação da Motivação para a Aprendizagem [Eama]} de Paulino, Sá e Silva (2015) - comporta duas subescalas, referentes a crenças motivacionais e a estratégias de regulação da motivação. Utilizou-se a subescala das estratégias de regulação motivacional - versão adaptada à Educação Superior: 30 itens divididos em 8 categorias: regulação do interesse situacional (procuro fazer dessa tarefa uma atividade agradável \#1); regulação das metas de resultado-aproximação (penso que preciso continuar trabalhando para ter bons resultados naquela disciplina \#2); regulação pela aplicação de autorreforços (estabeleço uma recompensa para quando conseguir finalizar meu trabalho \#14); regulação pela estruturação do contexto (tento não ter distrações à minha volta \#4); regulação pelo valor (tento relacionar aquela temática com assuntos de meu interesse \#9); regulação das metas de resultado-evitamento (penso que se não trabalhar posso ter que repetir a disciplina \#21); regulação das metas de aprendizagem (penso que aquele trabalho é importante para melhorar as minhas competências \#25); regulação pelas crenças sobre a eficácia pessoal (penso que sou capaz de realizar tarefas mesmo que sejam cansativas \#20).

\section{Questionário de Estratégias de Autorregulação do Controlo do Desempenho} [QEACD] de Deps, Simão e Silva (2012). Contém 21 itens divididos em 7 categorias: testar (para estudar, faço exercícios de revisão \#14); pedir ajuda (peço ajuda aos professores para esclarecer dúvidas \#12); rever (quando estudo, reviso meus trabalhos acadêmicos \#10); gestão de tempo (só estudo às vésperas das provas/exames \#8); gestão da atenção (enquanto estudo tento ignorar o que pode me distrair \#19); avaliação do processo/monitorização do estudo, gestão emocional da ansiedade (participo das aulas, mesmo quando isso me provoca ansiedade \#7). 


\subsection{Procedimentos: recolha e tratamento}

Ao participarem da pesquisa, os estudantes assinaram o termo de consentimento livre e esclarecido, autorizando a utilização de seus depoimentos. Primeiro, escreveram sua narrativa, posteriormente, analisaram as escalas Eama e QEACD, identificando as estratégias utilizadas com mais frequência, bem como as consideradas as mais eficazes para o sucesso acadêmico. No final, comentaram as escolhas realizadas, explicitando por que elas são importantes para o sucesso acadêmico.

A frequência das respostas das escalas Eama e QEACD foi submetida ao software NVivo-11, visando a compreender o fenômeno em questão. Emergiram categorias que foram analisadas por dois juízes externos envolvidos com a temática da investigação, obtendo-se um percentual de 90\% de acordo (AMADO, 2017). Para ilustrar os resultados, destacam-se excertos hauridos dos depoimentos dos estudantes, os quais intercruzados com a teoria responderam aos objetivos desta investigação. Os excertos foram identificados pela letra do país (P-Portugal, B-Brasil) e acompanhados do número do participante (1 até 19).

\subsection{Apresentação e discussão dos resultados}

Emergiram da triangulação dos dados, três categorias: atribuições de insucesso; motivação e estratégias autorregulatórias; expectativas em relação ao futuro.

\section{Atribuições de insucesso}

\subsection{Motivos internos de insucesso dos estudantes da Educação Superior}

Os motivos internos de insucesso dos estudantes da Educação Superior apresentam, nos dois países, variáveis pessoais, fortemente ligadas à desmotivação, ansiedade, falta de persistência e a situações ligadas à falta de planejamento estratégico, conforme mostra o Quadro 1.

Quadro 1 - Motivos internos de insucesso dos estudantes da Educação Superior

\begin{tabular}{|l|c|c|c|c|}
\hline Indicadores & \multicolumn{2}{|c|}{ Brasil (n.19) } & \multicolumn{2}{c|}{ Portugal (n.19) } \\
\hline Desmotivação & 6 & $(5,6,9,11,12,13)$ & $\mathbf{8}$ & $(1,6,7,8,10,12,16,17)$ \\
\hline Ansiedade & 3 & $(6,10,16)$ & $\mathbf{3}$ & $(5,11,15)$ \\
\hline Falta de persistência & 3 & $(5,13,4)$ & $\mathbf{8}$ & $(1,2,3,7,8,1416,19)$ \\
\hline
\end{tabular}


Continuation

\begin{tabular}{|l|c|c|c|c|}
\hline Indicadores & \multicolumn{2}{|c|}{ Brasil (n.19) } & \multicolumn{2}{c|}{ Portugal (n.19) } \\
\hline $\begin{array}{l}\text { Dificuldade de gerenciar } \\
\text { emoções }\end{array}$ & 6 & $(2,5,7,10,11,13)$ & $\mathbf{4}$ & $(6,8,15,18)$ \\
\hline $\begin{array}{l}\text { Baixa identificação com o } \\
\text { curso }\end{array}$ & 3 & $(5,11,18)$ & $\mathbf{3}$ & $(3,4,17)$ \\
\hline Dificuldades na aprendizagem & 3 & $(4,8,15)$ & $\mathbf{3}$ & $(4,6,15)$ \\
\hline $\begin{array}{l}\text { Falta de planejamento } \\
\text { estratégico }\end{array}$ & 9 & $(2,4,8,9,10,11,13,15,16)$ & $\mathbf{1 2}$ & $(1,2,3,4,5,6,7,8,10,14,18,19)$ \\
\hline
\end{tabular}

Fonte: Narrativas dos estudantes (2019)

Em relação à desmotivação, os estudantes brasileiros salientam que não se concentram. Dos 19 estudantes portugueses, 12 fazem referência às dificuldades de planejamento e concentração, que levam à perda da vontade de estudar. Um deles destaca: "estou tentando encontrar motivação extra para concluir o curso" (P16). Seis estudantes, três de cada país, dizem estar propensos a dividir a atenção entre a tarefa a ser realizada e os pensamentos decorrentes da ansiedade. Consideram que a ansiedade interfere, aumenta o desânimo e o fracasso, por conseguinte, sentem vergonha, embaraço e formam a imagem de que não conseguirão concluir a graduação: "muitas vezes dá uma angústia, uma vontade de desistir, pois o trajeto não é fácil" (B16). Estudantes portugueses pactuam com a mesma ideia, P15 explica: "sou muito ansiosa"; "quando chega a altura de avaliação fico apática e acabo me medicando com um antidepressivo" (P11). A falta de persistência torna-se notória nas falas dos entrevistados: "sou negligente com os estudos, não estou tendo sucesso para minha desejada formatura. Busco meios de superar minhas expectativas, penso que estou doente" (B5); "o que mais quero é melhorar e me sentir útil, sinto que deste modo estou caminhando para uma tristeza profunda, que me prejudica a cada dia" (B13).

Estudantes não persistentes evidenciam falhas em seu desempenho acadêmico, adiam compromissos, não entregam trabalhos, acumulam tarefas (SIMÃO; FRISON, 2013; ZIMMERMAN, 2013). Não perseverar na proposta de trabalho leva a procrastinar, a falhar, a agir de modo inconsequente. Ao fraquejar, os estudantes não conseguem gerenciar a própria vida, como salientam Pelissoni e Polydoro (2017). Percebem-se pontos de convergências nos depoimentos: "gostaria de ser mais aplicada, mais concentrada" (P14); "faço um esforço tremendo para concluir a tarefa, mas logo me disperso com outra coisa, vou ajudar meu pai na oficina e não volto ao estudo" (P16).

Em relação aos motivos internos de insucesso, nove estudantes brasileiros referem falta de planejamento. Um deles destaca: "utilizo de estratégias de estudo que 
deixam a desejar, estudo à noite, sendo que, às vezes, deixo de dormir para estudar, isso tem me debilitado" (B4). Especificamente 12, dos 19 participantes portugueses, expõem ter dificuldades de organizar um planejamento para aprender: "vim para a faculdade sem qualquer tipo de ritmo ou método de estudo, o que me levou a ter dificuldades nos exames" (P10); "deixo tudo para a última hora, limito-me a ir às aulas, fazer os trabalhos, os resumos. Estudar, deixo para a época dos exames, onde com certeza estarei mais estressada, por isso, não tenho tido o sucesso desejado" (P14).

Planejar é uma ação essencial em todas as etapas da vida, requer intencionalidade, consciência para automonitorar e mobilizar diferentes estratégias cognitivas, comportamentais ou motivacionais, como assinalam Pelissoni e Polydoro (2017), Simão e Frison (2013) e Zimmermam (2013). As pesquisas mostram que estudantes que desenvolvem competências autorregulatórias são beneficiados no sucesso acadêmico, devido ao engajamento ativo nas atividades e à motivação intrínseca. A falta de planejamento estratégico mostra que os estudantes não conseguem gerenciar o tempo disponível, provocando imenso desgaste físico e emocional. Consequentemente, tendem a se sentir pouco eficazes, desconfortáveis e com dificuldades para superar frustrações.

\subsection{Motivos externos de insucesso dos estudantes da Educação Superior}

O Quadro 2 expõe os motivos externos de insucesso, relacionadas aos contextos universitário e familiar e aos problemas financeiros enfrentados.

Quadro 2 - Atribuições externas de insucesso dos estudantes da Educação Superior

\begin{tabular}{|l|c|c|c|c|c|}
\hline Indicadores & Externas & \multicolumn{2}{|c|}{ Brasil (n.19) } & \multicolumn{2}{c|}{ Portugal (n.19) } \\
\hline \multirow{4}{*}{ Universitário } & $\begin{array}{c}\text { Método de Ensino utilizado } \\
\text { pelo professor }\end{array}$ & 5 & $(6,8,10,12,18)$ & $\mathbf{5}$ & $(8,9,10,11,12)$ \\
\cline { 2 - 6 } & $\begin{array}{c}\text { Relação de ajuda (pares e } \\
\text { professores) }\end{array}$ & 1 & $(6)$ & $\mathbf{4}$ & $(9,11,16,17)$ \\
\cline { 2 - 6 } & $\begin{array}{c}\text { Exigências e reorganização do } \\
\text { curso }\end{array}$ & 1 & $(6)$ & $\mathbf{4}$ & $(5,12,14,16)$ \\
\hline \multirow{3}{*}{ Familiar } & Doenças e perdas familiares & 3 & $(5,10,17)$ & $\mathbf{2}$ & $(8,19)$ \\
\cline { 2 - 6 } & $\begin{array}{c}\text { Mudança do contexto social e } \\
\text { familiar }\end{array}$ & 6 & $(2,3,7,11,13,15)$ & $\mathbf{6}$ & $(5,11,13,15,18,19)$ \\
\cline { 2 - 6 } & Dificuldade de gerenciar a vida & 3 & $(3,7,11)$ & $\mathbf{3}$ & $(11,15,18)$ \\
\hline Financeiro & Limitações financeiras & 3 & $(8,12,15)$ & & \\
\hline
\end{tabular}

Fonte: Narrativas dos estudantes (2019) 
Diferentes situações atravessam essa realidade. Um deles, por exemplo, refere-se ao sistema de Ensino - alguns professores têm dificuldades em promover e estimular a aprendizagem dos estudantes. Outro refere-se ao processo de aprendizagem, à falta de perspectivas de longo prazo, o que leva os estudantes a atribuírem menos valor ao andamento de seu empenho acadêmico.

Dos estudantes brasileiros e portugueses, cinco expõem, como problema, o método de Ensino adotado pelos professores, considerando-o pouco estimulador. Esta consideração vai ao encontro das pesquisas de Panadero e Alonso Tapia (2014), ao explicarem que alguns professores trabalham com metodologias voltadas ao aprender, propondo a utilização de estratégias em sala de aula. Há necessidade de programas que promovam propostas estimuladoras do uso de estratégias de autorregulação e apresentem alternativas de práticas pedagógicas que impulsionem o desenvolvimento de estratégias de Ensino (BEAUMONT; MOSCROP; CANNING, 2014). Isto, certamente, se caracterizará como uma contribuição para a formação dos estudantes universitários. Nas palavras dos entrevistados: "um grande problema do curso é a didática dos professores, a falta de interesse em ensinar os estudantes" (B6); "não aprendo pela falta de objetividade e clareza de alguns professores" (B10); "já tive/tenho professores que mal conseguem explicar a matéria" (P11); "quase todas as aulas são em formato de palestra, é extremamente difícil retirar qualquer tipo de apontamentos" (P12); "o ensino é muito impessoal e, na grande maioria, altamente teórico" (P8).

\section{Motivação e estratégias autorregulatórias}

\subsection{Estratégias de autorregulação da motivação da aprendizagem mais utilizadas por estudantes da Educação Superior e as consideradas mais eficazes}

As estratégias de autorregulação da motivação da aprendizagem mais utilizadas por estudantes da Educação Superior e as consideradas mais eficazes estão apresentadas no Quadro 3. A estratégia predominante (12 estudantes portugueses e 18 brasileiros) foi a regulação das metas de resultado-evitamento e a regulação de metas de aprendizagem. Há, no entanto, uma divergência significativa, pois nenhum dos estudantes brasileiros considera esta estratégia importante, tendo 17 deles marcado a regulação das metas de resultado-aproximação como a mais relevante. 
Quadro 3 - Estratégias de autorregulação da motivação da aprendizagem mais utilizadas por estudantes da Educação Superior e as consideradas mais eficazes (EAMA)

\begin{tabular}{|c|c|c|c|c|c|}
\hline Dimensão & Descrição do item & $\begin{array}{c}\text { Utilizada } \\
\text { (P)* }\end{array}$ & $\begin{array}{l}\text { Utilizada } \\
\text { (B)* }\end{array}$ & $\begin{array}{c}\text { Eficaz } \\
(P)^{*}\end{array}$ & $\begin{array}{c}\text { Eficaz } \\
\text { (B)* }\end{array}$ \\
\hline $\begin{array}{l}\text { Regulação das } \\
\text { metas de resultado- } \\
\text { aproximação }\end{array}$ & $\begin{array}{l}\text { - Penso que é preciso } \\
\text { continuar a trabalhar para } \\
\text { ter bons resultados naquela } \\
\text { disciplina (\#2) }\end{array}$ & 12 & 17 & - & - \\
\hline $\begin{array}{l}\text { Regulação pela } \\
\text { aplicação de } \\
\text { autorreforço }\end{array}$ & $\begin{array}{l}\text { Decido que se conseguir } \\
\text { terminar o trabalho, a seguir } \\
\text { posso fazer alguma coisa de } \\
\text { que gosto (\#18) }\end{array}$ & 12 & - & 10 & - \\
\hline $\begin{array}{l}\text { Regulação pela } \\
\text { Estrutura do } \\
\text { Contexto }\end{array}$ & $\begin{array}{l}\text {-Tento não ter distrações à } \\
\text { minha volta (\#4) } \\
\text { - Procuro um local de } \\
\text { trabalho que torne a tarefa } \\
\text { mais agradável (\#10) } \\
\text { - Escolho um local o qual } \\
\text { facilite minha concentração } \\
\text { (\#19) }\end{array}$ & - & 14 & $\begin{array}{l}10 \\
11\end{array}$ & $\begin{array}{l}10 \\
13\end{array}$ \\
\hline Regulação pelo valor & $\begin{array}{l}\text {-Penso o quanto é } \\
\text { importante fazer o } \\
\text { trabalho proposto para ter } \\
\text { a matéria em dia (\#22) }\end{array}$ & - & 16 & - & - \\
\hline $\begin{array}{l}\text { Regulação das metas } \\
\text { resultado-evitamento }\end{array}$ & $\begin{array}{l}\text { - Penso que, se não me } \\
\text { empenhar, as minhas } \\
\text { classificações vão ser } \\
\text { prejudicadas (\#6) } \\
\text { - Penso que se não trabalhar } \\
\text { posso ter que repetir a } \\
\text { unidade curricular (\#21) } \\
\text { - Comprometo-me a } \\
\text { continuar pensando que } \\
\text { se não o fizer, posso ter } \\
\text { um resultado negativo no } \\
\text { trabalho (\#26) }\end{array}$ & 13 & 17 & - & - \\
\hline $\begin{array}{l}\text { Regulação de metas } \\
\text { de aprendizagem }\end{array}$ & $\begin{array}{l}\text {-Digo a mim próprio(a) que } \\
\text { devo continuar para adquirir } \\
\text { o maior conhecimento } \\
\text { possível (\#11) }\end{array}$ & 14 & - & 12 & 17 \\
\hline $\begin{array}{l}\text { Regulação pelas } \\
\text { crenças sobre } \\
\text { eficácia pessoal }\end{array}$ & $\begin{array}{l}\text { Penso que sou capaz de } \\
\text { realizar tarefas, mesmo que } \\
\text { sejam cansativas (\#20) }\end{array}$ & - & 16 & - & - \\
\hline
\end{tabular}

Fonte: Escala de Autorregulação da Motivação para a Aprendizagem (Eama) (2018)

* Frequência em cada país. 
A regulação pelas crenças sobre eficácia pessoal foi marcada como a mais utilizada por 16 estudantes, porém, não foi destacada como mais efetiva em nenhum dos dois países. Entende-se que os estudantes que a assumem como desafio estão motivados por variáveis pessoais, tais como expectativas de autoeficácia, metas de aprendizagem, interesses pessoais (PAULINO; SÁ; SILVA, 2015; WOLTERS; 2011). A regulação da motivação é componente fundamental para a autorregulação da aprendizagem (ZIMMERMAN; SCHUNK, 2008), constituindo uma ação mediadora pela qual o indivíduo age de forma intencional, a fim de iniciar, manter ou reforçar seu nível de motivação. O professor, ao considerar os aspectos motivacionais, as influências socioambientais e o investimento em estratégias autorregulatórias, contribui para potencializar a eficácia pessoal do estudante e fortalecer seu desempenho acadêmico, reafirmando que a autorregulação da aprendizagem tem relação direta com a melhora da eficácia da aprendizagem e do rendimento acadêmico. (OLIVEIRA; STEIN, 2018). A melhor fonte geradora de autoeficácia estudantil manifesta-se quando ele se percebe capaz de realizar uma tarefa com sucesso. "As crenças de autoeficácia exercem influência nas escolhas, no grau de investimento, no esforço a ser dispendido e, também, no uso de estratégias de aprendizagem, variável tida como preditora do sucesso escolar dos estudantes" (CASIRAGHI; BORUCHOVITCH; ALMEIDA, 2020, p. 31) e da motivação para aprender, fortalecendo os estudantes que se julgam capazes de aprender.

\subsection{Estratégias de autorregulação de controle do desempenho utilizadas por estudantes da Educação Superior e as consideradas mais eficazes}

Das 7 dimensões abordadas (Quadro 4), 16 estudantes brasileiros e 12 portugueses consideraram essencial a gestão da atenção no processo de aprendizagem. Estudantes de ambos países destacaram "pedir ajuda" como estratégia eficaz para aprender. Entende-se que pedir ajuda envolve competências metacognitivas e autorreguladoras, contribuindo significativamente para que o estudante aprenda algo antes não compreendido. Tratase de uma percepção acerca do próprio processo de aprendizagem. Oliveira, Luz e Oliveira (2020) destacam que o professor precisa, cada vez mais, desempenhar o papel de mediador nos processos de ensinar e de aprender, promovendo caminhos para a autonomia. Na presente pesquisa, foi encontrada divergência em relação a tirar dúvidas em sala de aula: um brasileiro e quatro portugueses explicaram que não o fazem por acreditar que isso revela não saber. Ressalta-se, pois, a importância de o professor organizar espaços e propostas de trabalho nos quais a procura de ajuda efetivamente aconteça (SERAFIM; BORUCHOVITCH, 2010).

A estratégia "testar" só foi assinalada por 11 estudantes portugueses, quer como eficaz, quer como uma das mais utilizadas. Os estudantes brasileiros não consideraram esta possibilidade. 
Quadro 4 - Estratégias de autorregulação de controle do desempenho utilizadas por estudantes da Educação Superior e as consideradas mais eficazes (QEACD)

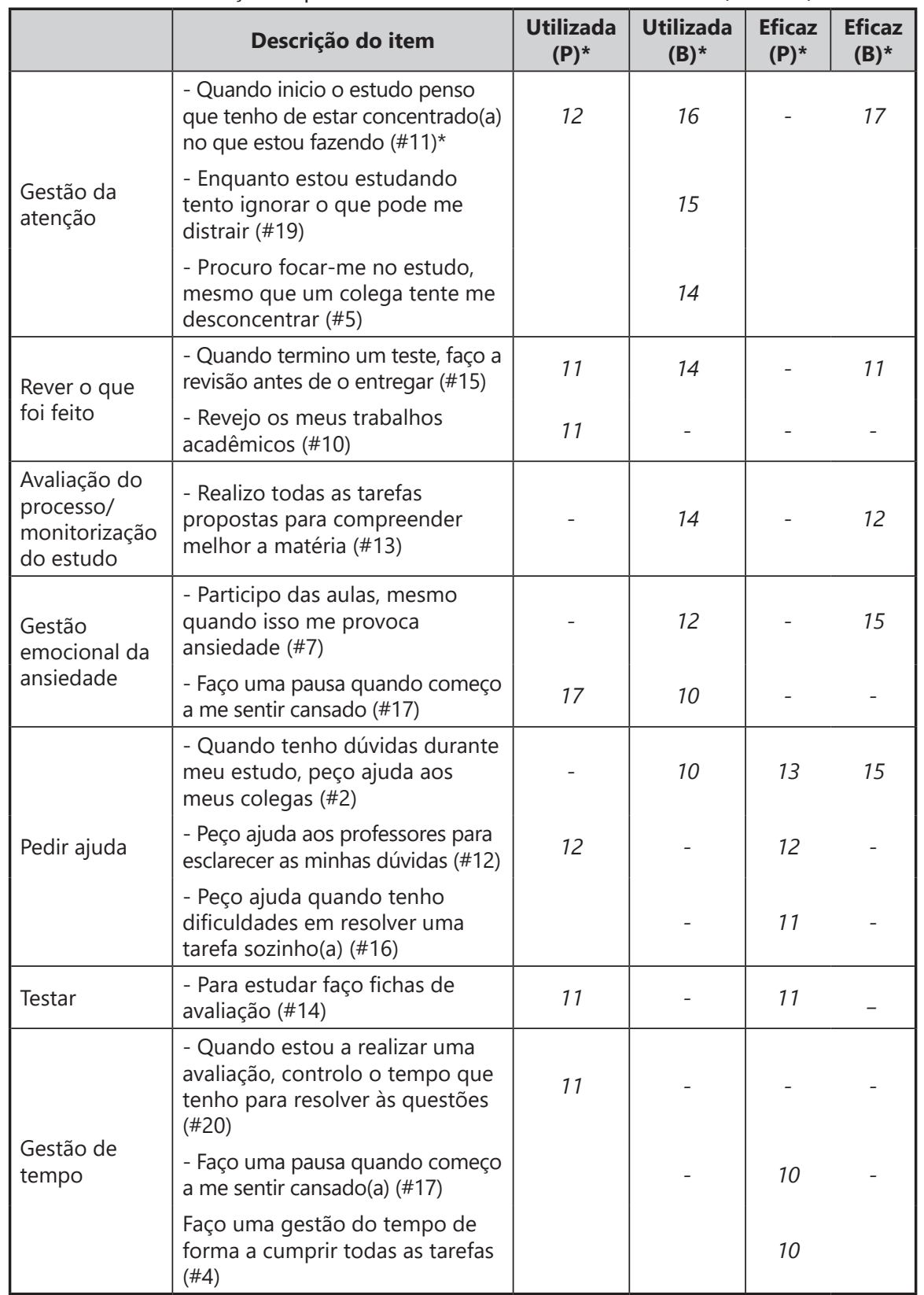

Fonte: Questionário de Estratégias de Autorregulação do Controlo do Desempenho [QEACD] (2018)

* Frequência em cada país. 
Em relação à "gestão emocional da ansiedade", estudantes portugueses e brasileiros dizem que ela faz parte de sua vida, no entanto, os portugueses não a marcaram nem como utilizada, nem como eficaz, explicando que não conseguem lidar bem com ela. Há uma divergência significativa entre portugueses e brasileiros em relação à ansiedade, pois estes últimos revelam participar das aulas, mesmo quando isso lhes provoca ansiedade. Percebe-se que os estudantes mobilizam poucas estratégias para regulação das emoções inerentes às novas exigências acadêmicas, entre as quais está a regulação de sentimentos como a ansiedade (ALMEIDA, 2019; CASIRAGHI; BORUCHOVITCH; ALMEIDA, 2020).

A gestão de tempo é, para a maioria dos estudantes, uma questão central, pois eles não sabem administrar nem gerenciar as várias tarefas assumidas. Observase que 10 estudantes portugueses consideram eficaz fazer uma pausa quando começam a se sentir cansados, porém, os estudantes brasileiros não consideram isto relevante. Casiraghi et al. (2020) esclarecem que alguns estudantes apresentam dificuldades na gestão do tempo e que a falta de estratégias para regulá-la eleva a ansiedade frente às novas exigências acadêmicas. Entende-se que os estudantes que apresentam melhores resultados acadêmicos são aqueles que mais bem distribuem seu tempo, de acordo com a dificuldade e a importância das tarefas. O tempo constitui fator crucial no planejamento e na execução de atividades diárias.

\section{Expectativas em relação ao futuro}

Tanto os eventos do passado como os do presente influenciam o modo como os indivíduos pensam e definem seu comportamento futuro. No Quadro 5, apresentam-se as expectativas dos estudantes em relação ao futuro.

Quadro 5 - Expectativas em relação ao futuro

\begin{tabular}{|l|c|c|c|c|}
\hline Indicadores & \multicolumn{2}{|c|}{ Brasil } & \multicolumn{2}{c|}{ Portugal } \\
\hline $\begin{array}{l}\text { Visão que o curso abra perspectiva } \\
\text { de futuro }\end{array}$ & 7 & $\begin{array}{c}(1,4,6,7,10,14, \\
15,16)\end{array}$ & $\mathbf{3}$ & $(3,6,16)$ \\
\hline $\begin{array}{l}\text { Visão que o curso os qualifica } \\
\text { profissionalmente }\end{array}$ & 4 & $(1,4,5,9)$ & $\mathbf{4}$ & $(1,3,14,17)$ \\
\hline Visão positiva do seu futuro no curso & 5 & $(1,2,7,15,17)$ & $\mathbf{8}$ & $(2,3,6,9,10,13,17,19)$ \\
\hline Visão negativa do seu futuro no curso & 1 & $(11)$ & $\mathbf{3}$ & $(7,8,11)$ \\
\hline Visão negativa do sentido do curso & 2 & $(12,14)$ & $\mathbf{6}$ & $(1,6,8,10,12,18)$ \\
\hline
\end{tabular}

Fonte: Narrativas dos estudantes (2019) 


\subsection{Visão positiva do curso}

Os estudantes que estão orientados em relação a seu futuro colocam forte ênfase no curso, no planejamento, na organização, no estabelecimento de metas para o alcance de objetivos de longo prazo. Alguns referem, com mais frequência, a percepção de que o curso os ajudará a se realizarem profissionalmente - "é um curso que abrirá muitas portas para o meu financeiro" (B6); "espero me formar no curso de odontologia, pois estarei alcançando minha independência realizando-me profissionalmente" (B7); "minhas expectativas em relação ao curso é ingressar na pós-graduação, me preparar para ser um profissional pronto para exercer minha profissão com dedicação e respeito" (B4). Os estudantes portugueses especificam: "sinto-me privilegiado em poder frequentar um curso superior, quando outros não o podem fazê-lo" (P3); "acredito que o curso de engenharia seja importante para meu crescimento profissional, possibilitando crescer na empresa" (P16). Estes comportamentos, na maioria dos casos, levam a consequências positivas em relação ao sucesso acadêmico (BOYD; ZIMBARDO, 2005).

Há convergência nos depoimentos de estudantes brasileiros e de portugueses ao explicitarem que os cursos os qualificam profissionalmente: "me vejo como um profissional em formação com as mesmas obrigações e atitudes de um profissional que atua na área" (B4); "quero me encaixar no mercado de trabalho como muitos de meus colegas" (B5); "espero daqui a dois anos ter terminado o curso e logo ser treinador, o que chamam de manager, gestor de equipe" ( P1); "espero que o curso me dê ferramentas para ser uma boa psicóloga" (P17). Os estudantes com histórico de insucesso confrontam-se com os desafios do presente, reconhecem e valorizam experiências que podem se tornar referências para suas expectativas e seus objetivos pessoais em relação ao futuro (ALMEIDA, 2019). Alguns estudantes projetam, no curso, trajetórias assertivas rumo ao futuro: "buscarei uma vaga no mercado de trabalho, vejo o geoprocessamento como com abrangência na região e muitas oportunidades de crescer" (B15); "gosto do curso que escolhi e não quero desperdiçar a oportunidade que me foi dada (P2).

\subsection{Visão negativa do curso}

Existem diferentes modos de projetar o futuro, principalmente quando envolve recompensas imediatas ou distantes. $\mathrm{O}$ valor percebido da recompensa adiada associa-se diretamente ao fato de o estudante não perceber se terá gratificação com o curso e com a profissão. Isso transparece nos depoimentos de três estudantes portugueses e brasileiros, os quais assim se expressaram: "neste momento não tenho nenhuma expectativa em relação ao futuro" (P7); "tenho muito poucas razões para realisticamente esperar algo positivo do meu futuro curso" (P8); 
"acho que o melhor é não ter expectativa futura, me desiludi bastante ao longo do curso" (P11).

Para alguns dos entrevistados (seis portugueses, dois brasileiros), há grande distância entre o que é ensinado na Graduação e o que é exigido pelo mundo do trabalho porque grande parte do conteúdo dos cursos é de cunho teórico, e não prático, dificultando a aplicação do conhecimento na vida profissional; muitos professores não orientam para as possibilidades de trabalho ofertadas no mercado; há pouco investimento direcionado aos campos práticos de trabalho e de inserção profissional. Outros (oito portugueses, cinco brasileiros) consideram que o ensinado e as intervenções realizadas em sala de aula não contribuem para o futuro desempenho profissional: "talvez devesse pensar menos nestes assuntos interesse e limitar-me a cursar as disciplinas que me inscrevi" (P1); "vou ter que me adaptar ainda que a realidade do curso possa estar distante da realidade" (P6); "não tenho expectativas, elas podem me desiludir e prefiro estar com a "mente aberta" (P18). Ações direcionadas para o futuro facilitariam o ingresso no mercado de trabalho, possibilitando uma adequada tomada de decisão profissional.

Há evidências da visão negativa sobre a escolha do curso. Três estudantes revelam "não quero continuar, não me adaptei, não terei futuro nele" (B12); "tenho expectativas relativamente baixas para o meu futuro, há poucas saídas profissionais relativamente a este curso" (P12).

Em tempo de intensas mudanças no meio acadêmico, é necessário divulgar amplamente informações concernentes ao trabalho e à carreira e discuti-las. Ao propiciar a discussão sobre condições de trabalho futuras, a universidade contribuirá socialmente para o planejamento de carreira e a inserção profissional de seus estudantes.

\section{Considerações finais}

Nos contextos pesquisados, verificaram-se convergências nos resultados, os quais indicam escasso comportamento adaptativo associado ao desenvolvimento de competências para aprender. Isto remete à importância da promoção do desenvolvimento de competências como meio de oferecer condições mais favoráveis à aprendizagem, para que os estudantes valorizem sua formação e seu curso. É importante estimular os universitários a serem bem-sucedidos, porém, isso depende, em larga escala, das escolhas de aprendizagem e do desenvolvimento de competências que fizerem durante o percurso acadêmico. Estabelecer metas, planejar objetivos, executar tarefas, autoavaliar sua organização acadêmica são ações pouco valorizadas nas perspetivas atuais e futuras dos participantes. 
Os estudantes da Educação Superior, precisam investir na definição de metas para seu futuro e desenvolver competências de análise e integração de informações, para situarem-se e comprometerem-se com atitudes e ações que os levem a ter melhor desempenho acadêmico. Os dados desta pesquisa sugerem que os estudantes dos dois países têm expectativas positivas em relação à sua permanência no curso. Cabe aos professores e aos contextos universitários investirem no oferecimento de oportunidades para que os alunos desenvolvam suas competências de autorregulação e tornem-se capazes de persistir, apesar dos obstáculos.

A Educação Superior requer a promoção de um conjunto de competências consideradas essenciais para o estudante universitário, entre as quais se destacam pensar, cooperar, gerir emoções, ser crítico, estabelecer as próprias metas. Estudar e conhecer percursos e estratégias utilizadas pelos estudantes mostram-se relevantes, sendo igualmente pertinente refletir sobre as metodologias docentes no Ensino e sobre a avaliação discente. O combate ao insucesso acadêmico poderá incluir o desenho e a implementação de programas de promoção de estratégias autorregulatórias e crenças motivacionais; a análise das práticas pedagógicas dos docentes; as opções de avaliação de conhecimentos; o feedback fornecido aos estudantes (CASIRAGHI; BORUHOVITHC; ALMEIDA, 2020). Em particular, a reformulação do currículo e das práticas pedagógicas; o desenvolvimento de novos cursos/planos de estudos; a ampliação da percpeção de utilidade do curso no mundo do trabalho evidenciam-se essenciais para a motivação dos estudantes e o desenvolvimento de políticas educacionais mais efetivas. Salienta-se que a democratização da Educação Superior, ocorrida nas últimas décadas, implica a garantia de equidade nas condições de acesso e de frequência ao curso. Por conseguinte, na avaliação das instituições de Educação Superior, torna-se fundamental contabilizar não só o número de estudantes ingressantes, mas também o de diplomados. Para formar estudantes com a devida habilitação para o ingresso no mercado de trabalho é essencial abordar o grau de envolvimento dos estudantes nos cursos que frequentam. Por este motivo, as instituições de Ensino são hoje desafiadas a rever suas políticas e práticas educativas em prol da permanência dos discentes e de seu sucesso acadêmico (ALMEIDA; ALMIRO, 2020). Sugere-se que estudos futuros, com amostras amplas e diversificadas, explorem variáveis individuais, como a aquisição de estratégias, o desenvolvimento de adequados processos cognitivos, metacognitivos e motivacionais na aprendizagem e variáveis contextuais, visando a ambientes de aprendizagem integrativos, holísticos e tolerantes, que valorizem o processo de aprendizagem. 


\section{Higher education students' paths with unsuccessful trajectories}

\section{Abstract}

This study analyzes unsuccessful trajectories, identifies reasons, strategies and expectations perceived by 38 students (19 Portuguese and 19 Brazilians), who elaborated a self-training narrative and answered two scales to evaluate self-regulation strategies according to their effectiveness and use. Students showed similar response patterns and reflected beliefs and strategies that are poorly adaptive to learning. Demotivation, anxiety, lack of persistence and the characteristics of the university and family contexts were perceived as the main reasons for failure. Students reported that the most used strategy was regulation based on the result-avoidance goals and the most effective was attention management. They also revealed a positive view of the course's value for the future, but identified a great discrepancy between the content taught and the requirements of the professional world.

Keywords: University Students. Narratives. Failure. Strategies.

\section{Recorridos de estudiantes de Educación Superior con trayectorias sin éxito}

\section{Resumen}

El estudio analiza las trayectorias de fracasso e identifica razones, estrategias y expectativas percibidas por 38 estudiantes - 19 portugueses y 19 brasileños - que elaboraron una narrativa de autoformación y comentaron en dos escalas para evaluar las estrategias de autorregulación, según su efectividad y uso. Los estudiantes muestran patrones de respuesta similares y reflejan creencias y estrategias que no se adaptan bien al aprendizaje. La desmotivación, la ansiedad, la falta de persistencia y las características del contexto universitario y familiar se perciben como los principales motivos del fracaso. Los estudiantes refieren que la estrategia más utilizada es la regulación por las metas de evitación de resultados y la más efectiva, la gestión de la atención; revelan una visión positiva del valor del curso para su futuro, pero identifican una gran discrepancia entre los contenidos impartidos y las exigencias del mundo laboral.

Palabras clave: Estudiantes Universitarios. Narrativas. Fracaso. Estrategias. 


\section{Referências}

ALMEIDA, A. N. Insucesso e abandono escolares no ensino superior: o caso da Universidade de Lisboa. Lisboa: Educa, 2013.

ALMEIDA, L. Estudantes do ensino superior: desafios e oportunidades. Braga: Psicologia e Educação, 2019.

ALMEIDA, L. S.; ALMIRO, P. A. Percursos e vivências dos estudantes no Ensino Superior. Revista E-Psi, Coimbra, v. 9, n. 1, p. 1-8, 2020, p. 1-8

AMADO, J. Manual de investigação qualitativa em educação. Coimbra: Universidade de Coimbra, 2017.

BANDURA, A. Teoria social cognitiva no contexto cultural.

In. BANDURA, A.; AZZI, R. G. Teoria social cognitiva: diversos enfoques. Campinas: Mercado de Letras, 2017. p. 45-82.

BEAUMONT, C.; MOSCROP, C.; CANNING S. Easing the transition from school to HE: scaffolding the development of self-regulated learning through a dialogic approach to feedback. Journal of Further and Higher Education, v. 40, n. 3, p. 331-350, out. 2014. https://doi.org/10.1080/0309877X.2014.953460

BOYD, J. N.; ZIMBARDO, P. G. Time perspective, health and risk taking. In: STRATHMAN, A.; JOIREMAN, J. (orgs.). Understanding behavior in the context of time: theory, research and application. New Jersey: Lawrence Erlbaum, 2005. p. 85-107.

BRASIL. Ministério da Educação. Decreto n ${ }^{0}$ 7.234, de 19 de julho de 2010. Dispõe sobre o Programa Nacional de Assistência Estudantil - PNAES. Diário Oficial da União, 20 jul. 2010.

CASIRAGHI, B.; BORUCHOVITCH, E.; ALMEIDA, L. Crenças de autoeficácia, estratégias de aprendizagem e o sucesso acadêmico no Ensino Superior. Revista E-Psi, Coimbra, v. 9, n. 1, p. 27-38, maio 2020.

DEPS, V.; SIMÃO, A. M. V. ; SILVA, A. A. S. Construção de um Instrumento de Estratégias Volitivas pelo Método Q-SORT. In: LYRA, P. (org.).

Conhecimento em processo: ensaios interdisciplinares sobre linguagem e cognição. Rio de Janeiro: Tempo Brasileiro EDUENF, 2012. p. 221-242.

INSTITUTO NACIONAL DE ESTUDOS E PESQUISAS EDUCACIONAIS ANÍSIO TEIXEIRA - INEP. Censo da educação superior. Brasília, DF, 2017. 
ISHII, I.; KRASILCHIK, M.; LEITE, R.C. Diversidade de alunos: o caso da USP. Revista de Educação Pública, São Paulo, v. 23, n. 54, p. 681-700, set./dez. 2014. https://doi.org/10.29286/rep.v23i54.1896

KOIVUNIEMI, M. et al. Higher education students' learning challenges and regulatory skills in different learning situations. Infancia y Aprendizaje, Madrid, v. 40, n. 1, p. 19-55, jan. 2017. https://doi.org/10.1080/02103702.2016.1272874

MERETT, G. N. et al. Perfis de autorregulação da aprendizagem e motivação de estudantes universitários. Estudos de Psicologia, Campinas, v. 37, e180126, mar. 2020. https://doi.org/10.1590/1982-0275202037e180126

MIRANDA, C.; NONTICURI, A.; FRISON, L.M.B. Estratégias autorregulatórias para o controle do desempenho em estudantes universitários: mudanças após processo reflexivo. Revista de Estudios e Investigación en Psicologia y Educación, v. extra, n. 1, p. 264-268, dic. 2017. https://doi.org/10.17979/reipe.2017.0.01.2726

MIRANDA, M. A.; GUZMÁN, J. Análisis de la deserción de estudiantes universitarios usando técnicas de minería de datos. Formación Universitaria, La Serena, v. 10, n. 3, p. 61-68, jan. 2017. https://doi:10.4067/S071850062017000300007

OLIVEIRA, A. K. D.; LUZ, A. R. J. B.; OLIVEIRA, K. K. As possibilidades da utilização de técnicas de autorregulação da aprendizagem por alunos de graduação. Brazilian Journal of Development, Curitiba, v. 6, n. 3, p. 10228-10243, mar. 2020. https//:doi.org/10.34117/bjdv6n3-050

OLIVEIRA, L. H.; STEIN, L. M. A autorregulação, avaliação e promoção da aprendizagem por meio da prática de recuperação da memória. Psicologia Escolar e Educacional, São Paulo. v. 22, n. 1, p. 55-62, jan./abr. 2018. https://doi.org/10.1590/2175-35392018018540.

PANADERO, E.; ALONSO TAPIA, J. ¿Cómo autorregulan nuestros alumnos? Revisión del modelo cíclico de Zimmerman sobre autorregulación del aprendizaje. Anales de Psicologia, Murcia, v. 30, n. 2, p. 450-462, abr. 2014. http://dx.doi.org/10.6018/analesps.30.2.167221

PAULINO, P.; SÁ, I.; SILVA, A. L. Autorregulação da motivação: crenças e estratégias de alunos portugueses do $7^{\circ}$ ao $9^{\circ}$ ano de escolaridade. Psicologia: Reflexão e Crítica, Porto Alegre, v. 28, n. 3, p. 574-582, jul./set. 2015. https://doi.org/10.1590/1678-7153.201528316 
PELISSONI, A. M. S.; POLYDORO, S. A. J. Programas de promoção da autorregulação da aprendizagem. In: POLYDORO, S. A. J. (org.). Promoção da autorregulação da aprendizagem: contribuições da Teoria Social Cognitiva. Porto Alegre: Letra1, 2017. p. 20-33.

RICOEUR, P. Tempo e narrativa. São Paulo: Papirus, 1995. Tomo II.

SÁEZ, F. M. et al. Revisão sistemática sobre competências de auto-regulação da aprendizagem em estudantes universitários e programas intracurriculares para sua promoção. Formación Universitaria, La Serena, v. 11, n. 6, p. 83-98, dez. 2018. https://doi.org/10.4067/S0718-50062018000600083

SANTOS, A.; FERRAZ, A.; INÁCIO, A. Adaptação ao ensino superior: estudos no Brasil. In: ALMEIDA, L. Estudantes do ensino superior: desafios e oportunidades. Braga: Psicologia \& Educação, 2019. p. 65-98.

SERAFIM, T. M.; BORUCHOVITCH, E. O pedir ajuda: concepções dos estudantes do ensino fundamental. Estudos Interdisciplinares em Psicologia, Londrina, v. 1, n. 2, p. 159-171, jun. 2010.

SIMÃO, A. M. V.; FRISON, L. M. Autorregulação da aprendizagem: abordagens teóricas e desafios para as práticas em contextos educativos. Cadernos de Educação, Pelotas, v.45, p.13. maio/ago/ 201. p, 02-20. http://dx.doi.org/10.15210/caduc.v0i45.3814

SIMÃO, J.; SANTOS, S. M.; COSTA, A. Ensino Superior: uma visão para a próxima década. Lisboa: Gradiva. 2003.

STOTEN, D. Managing the transition: a case study of self regulation in the learning of first term business and management undergraduate students at an English university. PostCompulsory Education, v. 20, n. 4, p. 445-459, Apr. 2015. https://doi.org/10.1080/13596748.2015.1081753.

WEINER, B. The development of an attribution-based theory of motivation: a history of ideas. Educational Psychologist, [s. 1.], v. 45, n. 1, p. 28-36, Jan. 2010. https://doi.org/10.1080/00461520903433596

WEINER, B. Searching for the roots of applied attribution theory. In: GRAHAM, S.; FOLKES, V. S. (orgs.). Attribution theory: applications to achievement, mental health and interpersonal conflict. New York: Routledge, 2016. p. 1-13. 
WOLTERS, C. Regulation of motivation: contextual and social aspects. Teacher's College Record, New York, v. 113, n. 2, p. 265-283, 2011.

ZIMMERMAN, B. From cognitive modeling to self-regulation: a social cognitive career path. Educational Psychologist, Lafayette, v. 48, n. 3, p. 135-147, 2013. https://doi.org/10.1080/00461520.2013.794676

ZIMMERMAN, B.; SCHUNK, D. H. Motivation: An essential dimension of self-regulated learning. In: SCHUNK, D. H.; ZIMMERMAN, B. J. (orgs.). Motivation and self-regulated learning: theory, research, and applications. Mahwah: Erlbaum, 2008. p. 1-30.

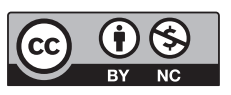

\section{Informações sobre as autoras}

Lourdes Maria Bragagnolo Frison: Doutorado e Pós-Doutorado em Educação pela Pontifícia Universidade Católica do Rio Grande do Sul. Professora Associada da Universidade Federal de Pelotas. Líder do Grupo de Estudos e Pesquisa da Aprendizagem Autorregulada, Programa de Pós-Graduação em Educação da Universidade Federal de Pelotas. Bolsista de produtividade Pq2. Projeto Universal. Conselho Nacional de Desenvolvimento Científico e Tecnológico. In memorian.

iD https://orcid.org/0000-0001-6671-5808

Ana Margarida Veiga Simão: Doutorado em Ciências da Educação e agregação em Psicologia da Educação. Professora Catedrática da Faculdade de Psicologia, Universidade de Lisboa, Investigadora do Centro de Investigação em Ciência Psicológica, Faculdade de Psicologia da mesma universidade. Contato: amsimao@psicologia.ulisboa.pt

iD https://orcid.org/0000-0003-3652-5573

Paula da Costa Ferreira: Doutorado em Psicologia da Educação. Investigadora do Centro de Investigação em Ciência Psicológica, Faculdade de Psicologia, Universidade de Lisboa e do Instituto de Engenharia de Sistemas e Computadores, Investigação e Desenvolvimento - Instituto Superior Técnico. Bolsista da Fundação para a Ciência e Tecnologia (SFRH/BPD/110695/2015). Contato: paula.costa.ferreira@gmail.com

iD https://orcid.org/0000-0001-8679-4566

Paula Paulino: Doutorado em Psicologia da Educação. Professora Auxiliar na Escola de Psicologia e Ciências da Vida da Universidade Lusófona de Humanidades e Tecnologias. Investigadora do Centro de Investigação em Ciência Psicológica. Faculdade de Psicologia, Universidade de Lisboa. Contato: a.paula.paulino@gmail.com

iD https://orcid.org/0000-0001-8249-5366 